\author{
Ionel-Sorinel VASILCA, PhD Student \\ E-mail: sorinvasilca@gmail.com \\ Mihail BĂRĂNESCU, PhD Student (Corresponding Author) \\ E-mail: baranescumihail@yahoo.com \\ Professor Marius PROFIROIU, PhD \\ E-mail: profiroiu@gmail.com \\ The Bucharest University of Economic Studies \\ Professor Lasse BERNTZEN, PhD \\ E-mail: Lasse.Berntzen@usn.no \\ University of South-Eastern Norway \\ Associate Professor Codruta CHIS, PhD \\ E-mail: codrutachis@gmail.com \\ Banat University of Agricultural Sciences and \\ Veterinary Medicine, Timisoara \\ Associate Professor Madlena NEN, PhD \\ E-mail: madlenanen@yahoo.com \\ The Bucharest Military Technical Academy "Ferdinand I"

\section{QUANTITATIVE DATA ANALYSIS ON ABUSIVE CALLS GENERATED BY CHILDREN TO 112}

Abstract. This paper refers to the idea of using econometric models to optimize and increase the efficiency of the 112 emergency system in Romania. This article intends to analyze a part of non-emergency calls related to the abusive calls generated by children. The 112 emergency system in Romania has been established in Romania since 2004-2005. One main focus of the system administrator is to reduce the number of non-emergency calls and by this to contribute towards increasing the quality of services. This study will not focus on real emergency calls directed to first responders such as medical emergency services, firefighters and police forces. In this work, the data was analyzed in order to extract the relevant information about the root causes behind abusive calls. Keeping in mind that an important category of abusive calls is generated by children, we have focused the study on this aspect. Until now, there was an idea to increase the awareness of children about the emergency number, but it appears necessary to go deeper in this analysis in order to better understand the behavior of children and be able to adopt the best solution towards decreasing the number of abusive calls.

The results of the analysis per volume of calls, per national county and per distribution as types of non-emergency calls generated by children, may indicate to the 112 administrator how best to approach future improvements in dealing with reduction of such non-valuable calls to the emergency service.

Keywords: Emergency call, Children, Abusive calls, Non-emergency calls.

JEL Classification: C01, C29, C61, C83

DOI: 10.24818/18423264/54.2.20.13 
Ionel-Sorinel Vasilca, Mihail Bărănescu, Marius Profiroiu, Lasse Berntzen, Codruta Chis, Madlena Nen

\section{Introduction}

In any analysis we performed related to the number of abusive calls, one can see that there is some relation between the number of calls answered by operators and the quality of service offered by the 112 system. Since the number of 112 emergency calls is generally quite significant, we could not obtain relevant information from simple analysis made using tabular calculation.

Upon researching similar works at European or even a global level, we did not find too many similar studies, because the available literature analyses the distribution of emergency calls and not of non-emergency calls. These latter calls, along with those of an abusive nature, are different in nature and are treated differently abroad based on their national framework. If their own Law stipulated a high rate of penalties, they consequently did not face as many abusive calls as other, more lenient countries.

In statistical modeling, regression analysis represents a set of statistical processes for estimating the relationships between a dependent variable and one or more independent variables (Bates \& Watts, 1988). Regression is easy to use for establishing the correlation between the indicators we chose for analyzing the quality of 112 system.

Non-emergency calls generated to the 112 system contribute directly to the erosion of the quality of service and represent a considerable waste of resources. The administrator of the emergency 112 system therefore aims to decrease the volume of non-emergency calls by approaching their root causes.

This research paper intends to zoom in on non-emergency calls specifically generated by children, in an attempt at identifying if any calling patterns exist and at trying to establish correlations or dependencies according to the calls' time of day and distribution throughout the week. The times when children are regularly missing parental supervision at home and other such variables will be analyzed below (EENA Operations Committee 2011).

Once such relationships are confirmed by statistics, the administrator of the 112 national emergency system could calibrate the project of increasing awareness to the correct issues, in order to effectively reduce the number and duration of these abusive calls (https://www.sts.ro/ro/statistici-112).

In our paper, we investigated the main type of abusive calls and attempted to identify specific patterns that could be later used in a media campaign organized by the 112 system administrator.

\section{Literature review}

112 is managed and financed in the European Union by each member state (country), who also decide on the organization of the emergency call centres. Candidates for EU accession and members of the EEA agreement also adopt the number.

The International Telecommunications Union recommends in its Recommendation E.161.1 (ITU-T, 2012) that member states selecting a primary or secondary emergency number choose either 911,112 or both. However, findings 
regarding the perception of the citizen perspective also demonstrate the ability of exercise participants to meet and respond to public behaviors with respect and seriousness (Scott, Brandow, Hobbins et al., 2015).

Since 1956 Sweden has had an organisation for emergency management that is unique in the world. When somebody in Sweden dials 112 (which is the common European emergency number) that person will reach the closest of the 20 emergency coordination centres (ECC) in the country, in which several operators work around the clock receiving emergency phone calls from the public. The goal of an ECC is to dispatch the necessary and adequate resources as quickly as possible (Artman \&Wærn, 1999).

Due to the high volume of emergency calls, an automated scheme is required to answer and manage the calls. This will require more experimentation and development. Understanding the traffic patterns of an emergency communications system is difficult due to the availability of data and requires many estimates. (Deaton, 2008)

Two groups - Widiatmoko, Machen, Dickinson et al. (2008) in the United Kingdom, alongside Lehm, Andersen and Riddervold (2017) in Denmark - have previously studied medical emergency calls and identified which of these were non-urgent, meaning those calls that pertained to certain medical issues which were not classified as "urgent".

In order to optimize the call-taking process, Jakob Cromdal, Håkan Landqvist, Daniel Persson-Thunqvist and Karin Osvaldsson (2012) analyzed two different ways of answering emergency calls. They also studied the consequence of requesting more information once the operator answered the call.

Lee, Lau, Hazlett et al. (2000) performed a study in Hong Kong about the factors that influence the non-urgent utilization of their emergency system, focusing on the social standard of the people who were calling.

Mats Eriksson (2010) studied the influence of technology and social media on public expectations regarding the 112 emergency operators.

In the United States of America there is a department for Non-Urgent Emergencies. Honigman, Wiler, Rooks and Ginde (2013) took a national survey in order to optimize and reduce the cost of non-urgent medical calls.

The study carried out by Vertesi (2004) in Canada attempted to analyze the impact of more strict criteria for accepting patients to medical care services. The conclusion was that this will make citizens not call for emergency services lightly.

\section{The methodology}

The method used in this paper is based on regression analysis performed within the eView 10 University application and crosstab analysis performed using SPSS. A comprehensive study of statistics methods, tests and examples of interpretation presented by Howitt \& Cramer (2011) have been instrumental to our work. We have also used in our analysis the statistic definitions, methods and interpretations for behavioral sciences of Russo (2003).

Our objective was to clearly prove the negative effects brought on by the number and duration of non-emergency calls to the quality of the 112 emergency

\section{DOI: 10.24818/18423264/54.2.20.13}


Ionel-Sorinel Vasilca, Mihail Bărănescu, Marius Profiroiu, Lasse Berntzen, Codruta Chis, Madlena Nen

system. Towards this goal, we analyzed the largest categories of abusive calls Frivolous Calls, Malicious Calls and Prank Calls - and compared their distribution over the different counties, days of the week, hours of the day, as well as their originators, whether they were children or adults.

Based on the results we obtained from this analysis, we propose certain actions that need to be taken by the 112 emergency system administrator in order to increase the quality and efficiency of the service.

\section{Data collection}

In order to capture the relevant data regarding the abusive calls, we have added two new hierarchical fields to the 112 operator system interface and we have asked the operators to fill in these fields as soon as a non-emergency call is identified.

This data collection phase ran for a quarter of a year, starting from 1st September 2018.

The first field enabled us to record the flag that a child generated a particular non-emergency call, while the second field corresponded to one of the following values:

a) Frivolous Calls, meaning calls made by accident or just for fun, while playing with the phone's keypad or testing its functionalities.

b) Malicious Calls, meaning calls during which the emergency service or the 112 operators were insulted or otherwise gratuitously attacked.

c) Prank Calls, meaning calls that were intentionally dialed in order to create false alarm for the intervention of 112 agencies.

\section{Data processing}

The following top-down analysis shows the different distribution of abusive calls, split between adults and children, according to the call categories described earlier:

Table 1. Abusive Calls distributions adults vs. children

\begin{tabular}{|l|l|r|r|r|}
\hline \multicolumn{1}{|c|}{ Months } & Age Class & Frivolous Calls & Malicious Calls & \multicolumn{1}{c|}{ Prank Calls } \\
\hline September & Adults & 13,976 & 6,544 & 805 \\
\hline September & Children & 24,150 & 3,366 & 1,970 \\
\hline October & Adults & 13,684 & 7,385 & 808 \\
\hline October & Children & 27,110 & 3,625 & 1,875 \\
\hline November & Adults & 12,946 & 7,382 & 667 \\
\hline November & Children & 29,478 & 3,197 & 1,529 \\
\hline December & Adults & 16,299 & 8,593 & 621 \\
\hline December & Children & 28,641 & 3,159 & 1,365 \\
\hline
\end{tabular}

Throughout the analyzed period of time, the total number of abusive calls generated by children numbered 132,222 , with $82 \%$ of these represented by 
109,379 Frivolous Calls, $10 \%$ represented by 13,348 Malicious Calls and 5\% by 6,739 Prank Calls.

The graphical representation of the above values shows a different pattern for adults and children, depicted as following:

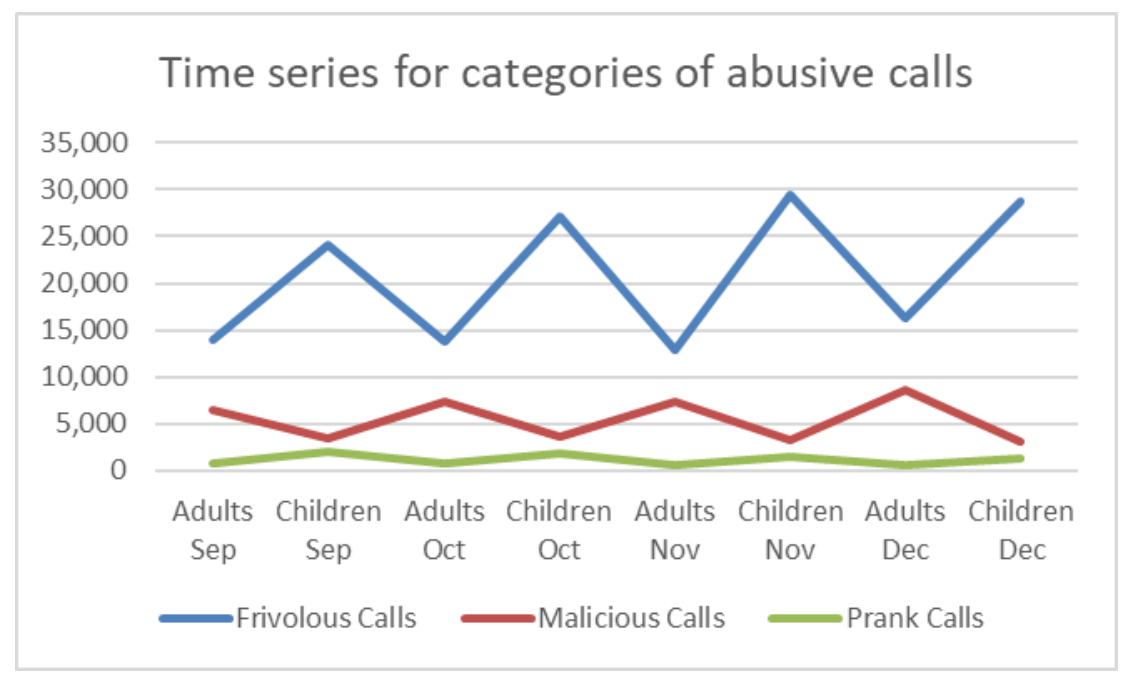

Figure 1.Time series for categories of abusive calls

The first observation we made was that the total number of abusive calls generated by children was about $25 \%$ higher than those generated by adults.

The second observation would be that Frivolous Calls represent the majority of abusive calls. Not only that, but they are twice as many as the Malicious Calls generated by adults and seven times greater than the ones generated by children.

There is even a study showing that the number of calls generated by children is not influenced by the fact that they are less aware and do not know what to do in an emergency (Moore, S., \& McCabe, A. E. 1996).

Following on that, one could therefore say that the Frivolous Calls generated by children are significantly higher in number than - and form almost a mirror image of - the Malicious Calls category, with the two graphs in Figure 1 above resembling a "saw tooth" pattern.

There was also a sizable difference noted between the numbers of Prank Calls generated by adults and those generated by children.

Whereas the Prank and Malicious Calls seemed to follow a constant trend, the Frivolous Calls distribution was actually ascending, meaning that stopping its progress and reducing this particular category of abusive calls as soon as possible would be instrumental to preserving the quality of the 112 emergency service.

The total of number of abusive calls per county, the waiting time until the operator answered the line and the cumulative duration of non-emergency calls are all represented in tabular and graphical form as follows:

DOI: 10.24818/18423264/54.2.20.13 
Ionel-Sorinel Vasilca, Mihail Bărănescu, Marius Profiroiu, Lasse Berntzen, Codruta Chis, Madlena Nen

The total number of abusive calls made to the 112 system in the $4^{\text {th }}$ quarter of 2018 reached 132,222 , collectively amounting to a total call duration of about 28 days.

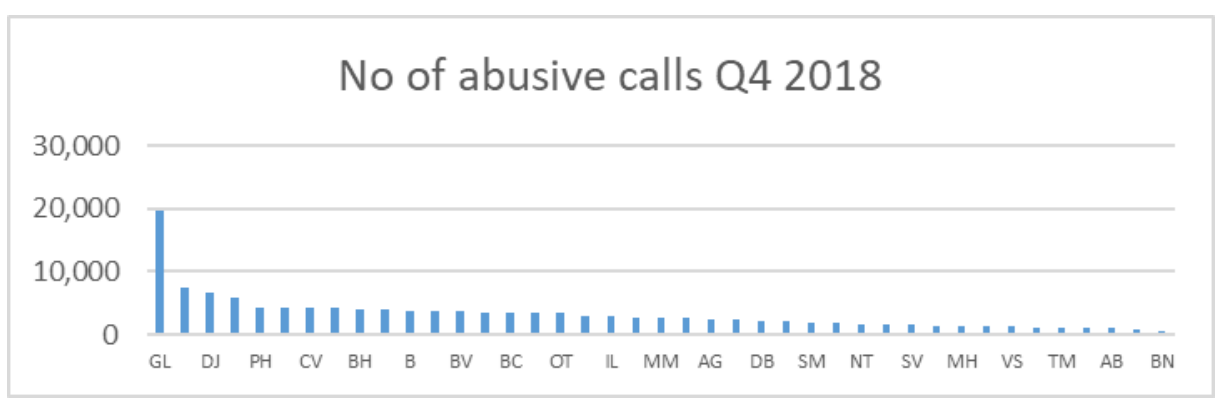

Figure 2. Abusive calls distribution per county

28 days of abusive calling take up the time of five shift operators. Should one take into consideration just the monthly salary of said operators, we stand to lose: 5 operators x approximately 1,000 EUR monthly salary $=5,000$ EUR lost each quarter, or 20,000 EUR lost per annum.

Even if the number of Prank Calls is relatively low, this category of abusive calls bears the highest cost to the State. If one considers that one real intervention costs roughly 500 EUR and that cost occurs only for 50\% of Prank Calls, we find: 6,739 child Prank Calls x 500 EUR x 50\% = approximately 1.5 million EUR lost per quarter, or roughly 6 million EUR lost per annum

Considering the above numbers, one can notice that the abusive calls generated by children alone are costing the State an amount in the range of 6 million EUR every year.

Compared to this figure, the 20,000 EUR cost represented by the salaries of the 112 operators is orders-of-magnitude less and appears almost trivial by comparison. The sheer cost of Frivolous and Malicious Calls directly impacts the quality of the 112 emergency service. This confirmation of the negative effects brought on by the number and duration of non-emergency calls was verified by running regression analysis via the eView application.

Regarding the duration of non-emergency calls, the abusive ones showed a mean of 18.2 seconds and a median of 12 seconds, while each abusive call waiting time had a mean value of 4.2 seconds and a median of 2 seconds, with both charts below illustrating a strong left skew.

Figure 3.Duration of abusive calls

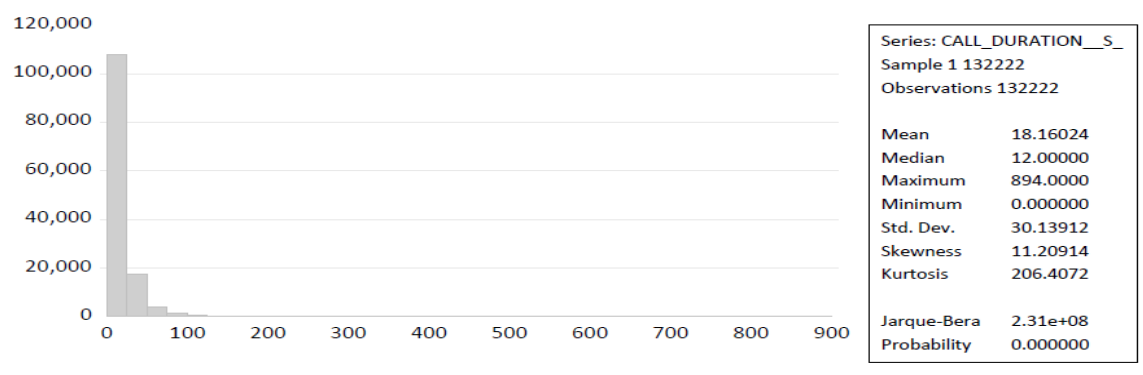




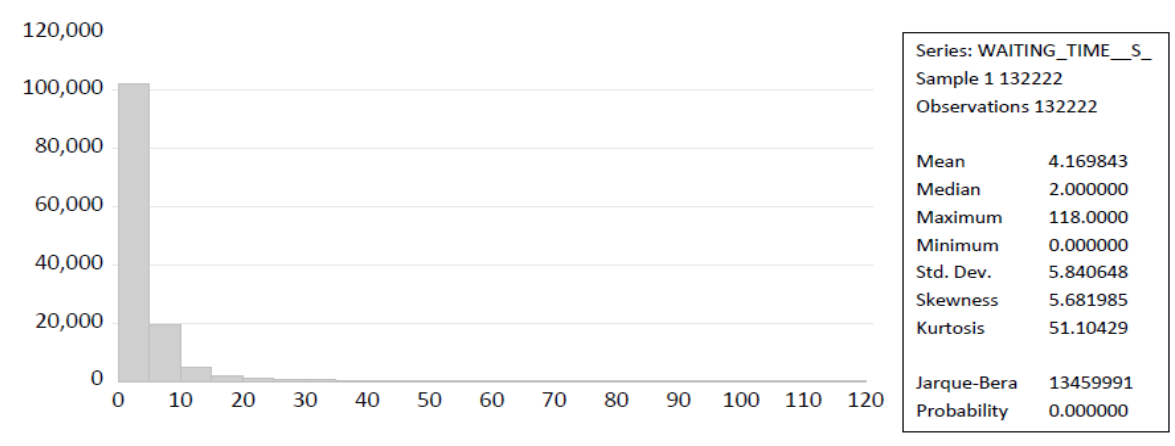

Figure 4. Waiting time for abusive calls

Considering that the call waiting time is an important parameter of a call centre performance - since its value represents the duration of time that someone in real need has to wait before they can report a genuine emergency - and the fact that emergency calls are still coming in between these non-emergency calls, it becomes increasingly clear that the 112 administrator has to take operational and technical actions in order to decrease the call waiting time as much as possible.

There is a direct linear relationship between the waiting time and the number of abusive calls, as can be seen by running the eView regression equation:

\begin{tabular}{|c|c|c|c|c|}
\hline \multicolumn{5}{|c|}{$\begin{array}{l}\text { Dependent Variable: WAITING TIME S } \\
\text { Method: Least Squares (Gauss-Newton / Marquardt steps) } \\
\text { Date: } 12 / 01 / 19 \text { Time: } 18: 48 \\
\text { Sample: } 142 \\
\text { Included observations: } 42 \\
\text { WAITING_TIME_S_C }(1)^{\star} \text { NO_OF_ABUSIVE_CALLS }\end{array}$} \\
\hline & Coefficient & Std. Error & t-Statistic & Prob. \\
\hline $\mathrm{C}(1)$ & 4.175451 & 0.020461 & 204.0688 & 0.0000 \\
\hline $\begin{array}{l}\text { R-squared } \\
\text { Adjusted R-squared } \\
\text { S.E. of regression } \\
\text { Sum squared resid } \\
\text { Log likelihood } \\
\text { Durbin-Watson stat }\end{array}$ & $\begin{array}{r}0.998918 \\
0.998918 \\
2766.402 \\
3.14 \mathrm{E}+08 \\
-391.9521 \\
1.575641\end{array}$ & \multicolumn{2}{|c|}{$\begin{array}{l}\text { Mean dependent var } \\
\text { S.D. dependent var } \\
\text { Akaike info criterion } \\
\text { Schwarz criterion } \\
\text { Hannan-Quinn criter. }\end{array}$} & $\begin{array}{l}26254.52 \\
84111.50 \\
18.71200 \\
18.75338 \\
18.72717\end{array}$ \\
\hline
\end{tabular}

Figure 5. Relation between the number of abusive calls and waiting time

The total waiting time is reduced about 4.2 times once the operator reduces the total number of abusive calls by just 1 .

There are several propositions towards reducing the number of abusive calls relating to the legal framework and the operation of the 112 service.

DOI: 10.24818/18423264/54.2.20.13 
Ionel-Sorinel Vasilca, Mihail Bărănescu, Marius Profiroiu, Lasse Berntzen, Codruta Chis, Madlena Nen

From the legal framework perspective, non-emergency calls - including the category of abusive calls - could be drastically reduced if the purchase of prepaid SIM cards would be possible only following an owner identity declaration.

Such legal action would discourage both children and adults from generating Frivolous, Malicious or Prank calls.

As an action from the operational side, the call waiting time could be decreased if incoming calls were not handled exclusively by 112 operators belonging to a county's jurisdiction, but rather by a dynamic pool of available 112 operators from all of the other counties.

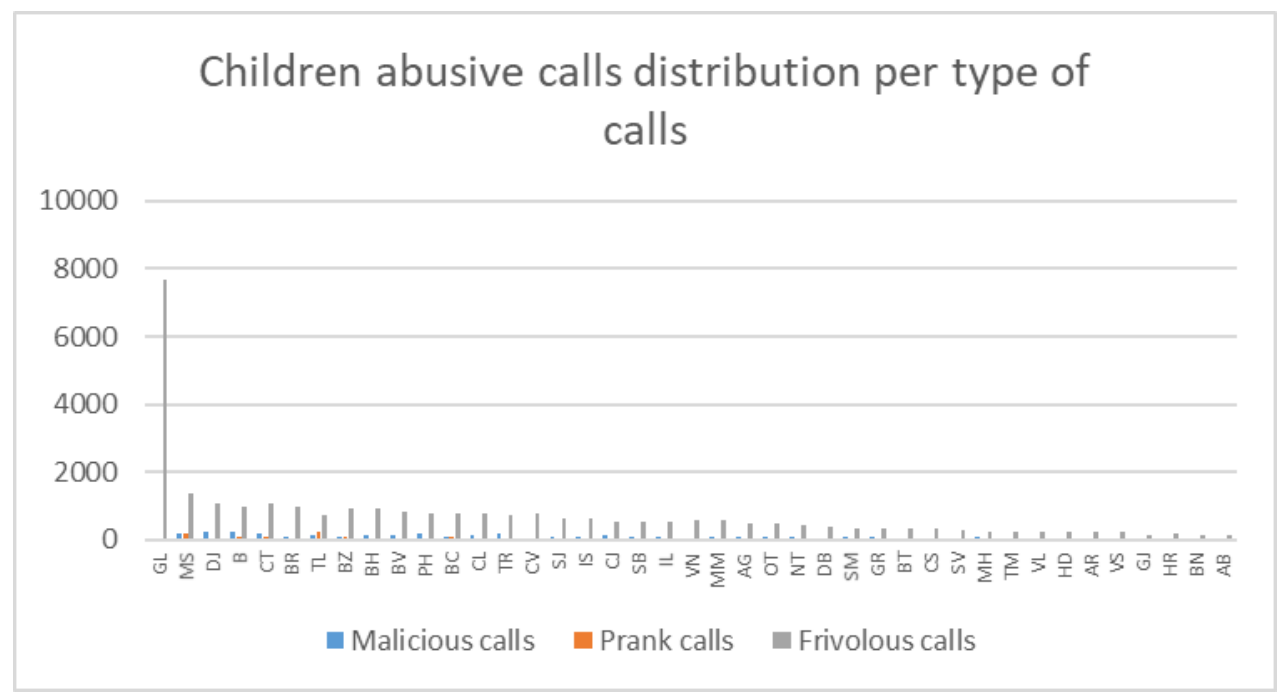

Figure 6. Children abusive calls distribution per type of calls

One other representation of the distribution between the three abusive call categories easily demonstrates the fact that Frivolous Calls hold the largest percentage nationwide when compared to Malicious and Prank Calls. Even if the financial losses they generate are not as high due to there not being any field interventions taking place in their case, the Frivolous and Malicious Calls are akin to a guerrilla war waged between the callers and the 112 operators, which only serves to keep the latter group busy while honest citizens are in need of genuine urgent intervention. follows:

The descriptive characteristics of the calls are summarized below as 
Quantitative Data Analysis on Abusive Calls Generated by Children to 112

\begin{tabular}{|c|c|c|c|c|}
\hline \multicolumn{5}{|c|}{$\begin{array}{l}\text { Empirical Distribution Test for CALL DURATION } \\
\text { Hypothesis: Normal } \\
\text { Date: } 12 / 01 / 19 \text { Time: } 21: 53 \\
\text { Sample: } 1109379 \\
\text { Included observations: } 109379\end{array}$} \\
\hline Method & Value & Adj. Value & Probability & \\
\hline Lilliefors (D) & 0.283315 & NA & 0.0000 & \\
\hline Cramer-von Mises (W2) & 2938.355 & 2938.368 & 0.0000 & \\
\hline Watson (U2) & 2826.339 & 2826.352 & 0.0000 & \\
\hline Anderson-Darling (A2) & 15769.34 & 15769.44 & 0.0000 & \\
\hline \multicolumn{5}{|c|}{ Method: Maximum Likelihood - d.f. corrected (Exact Solution) } \\
\hline Parameter & Value & Std. Error & z-Statistic & Prob. \\
\hline MU & 17.62948 & 0.090495 & 194.8126 & 0.0000 \\
\hline SIGMA & 29.92881 & 0.063990 & 467.7136 & 0.0000 \\
\hline Log likelihood & -526961.3 & Mean dep & ent var. & 17.62948 \\
\hline No. of Coefficients & 2 & S.D. deper & ent var. & 29.92881 \\
\hline
\end{tabular}

Figure 7. Empirical distribution for call duration of frivolous calls

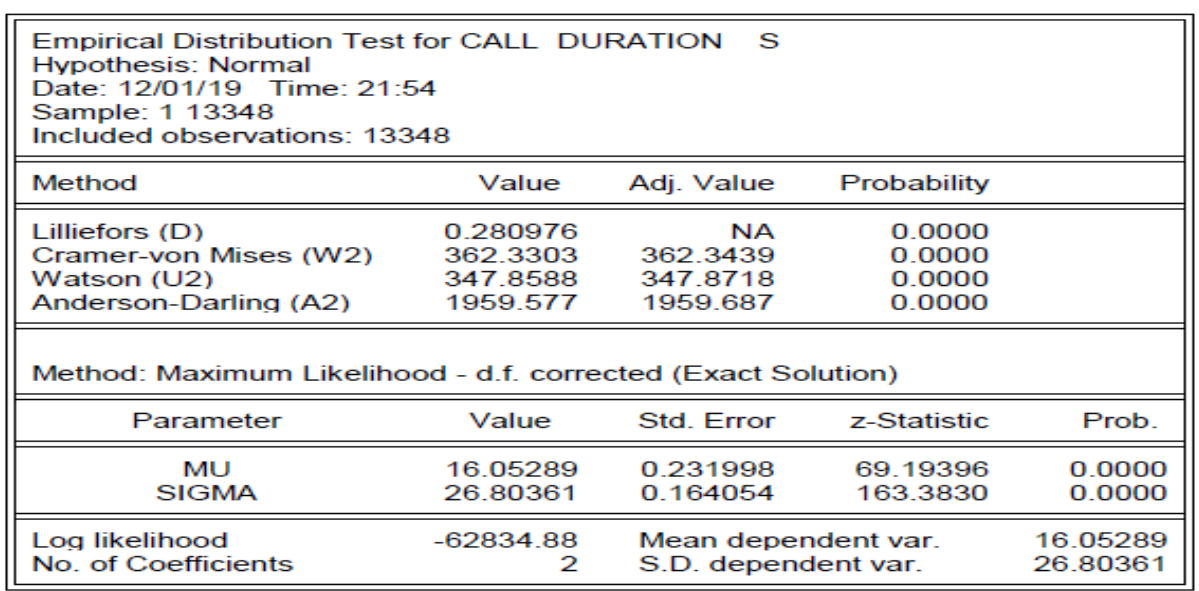

Figure 8. Empirical distribution for call duration of malicious calls

\begin{tabular}{|c|c|c|c|c|}
\hline \multicolumn{5}{|c|}{$\begin{array}{l}\text { Empirical Distribution Test for CALL DURATION S } \\
\text { Hypothesis: Normal } \\
\text { Date: } 12 / 01 / 19 \text { Time: } 21: 56 \\
\text { Sample: } 16740 \\
\text { Included observations: } 6740\end{array}$} \\
\hline Method & Value & Adj. Value & Probability & \\
\hline Lilliefors (D) & 0.182272 & NA & 0.0000 & \\
\hline Cramer-von Mises (W2) & 85.19587 & 85.20219 & 0.0000 & \\
\hline Watson (U2) & 75.09308 & 75.09865 & 0.0000 & \\
\hline Anderson-Darling (A2) & 477.3630 & 477.4161 & 0.0000 & \\
\hline \multicolumn{5}{|c|}{ Method: Maximum Likelihood - d.f. corrected (Exact Solution) } \\
\hline Parameter & Value & Std. Error & z-Statistic & Prob. \\
\hline MU & 30.82033 & 0.403826 & 76.32073 & 0.0000 \\
\hline SIGMA & 33.15314 & 0.285570 & 116.0948 & 0.0000 \\
\hline $\begin{array}{l}\text { Log likelihood } \\
\text { No. of Coefficients }\end{array}$ & $\begin{array}{r}-33160.81 \\
2\end{array}$ & \multicolumn{2}{|c|}{$\begin{array}{l}\text { Mean dependent var. } \\
\text { S.D. dependent var. }\end{array}$} & $\begin{array}{l}30.82033 \\
33.15314\end{array}$ \\
\hline
\end{tabular}

Figure 9. Empirical distribution for call duration of prank calls 
Ionel-Sorinel Vasilca, Mihail Bărănescu, Marius Profiroiu, Lasse Berntzen, Codruta Chis, Madlena Nen

Finally, a cumulative view according to call type and county:

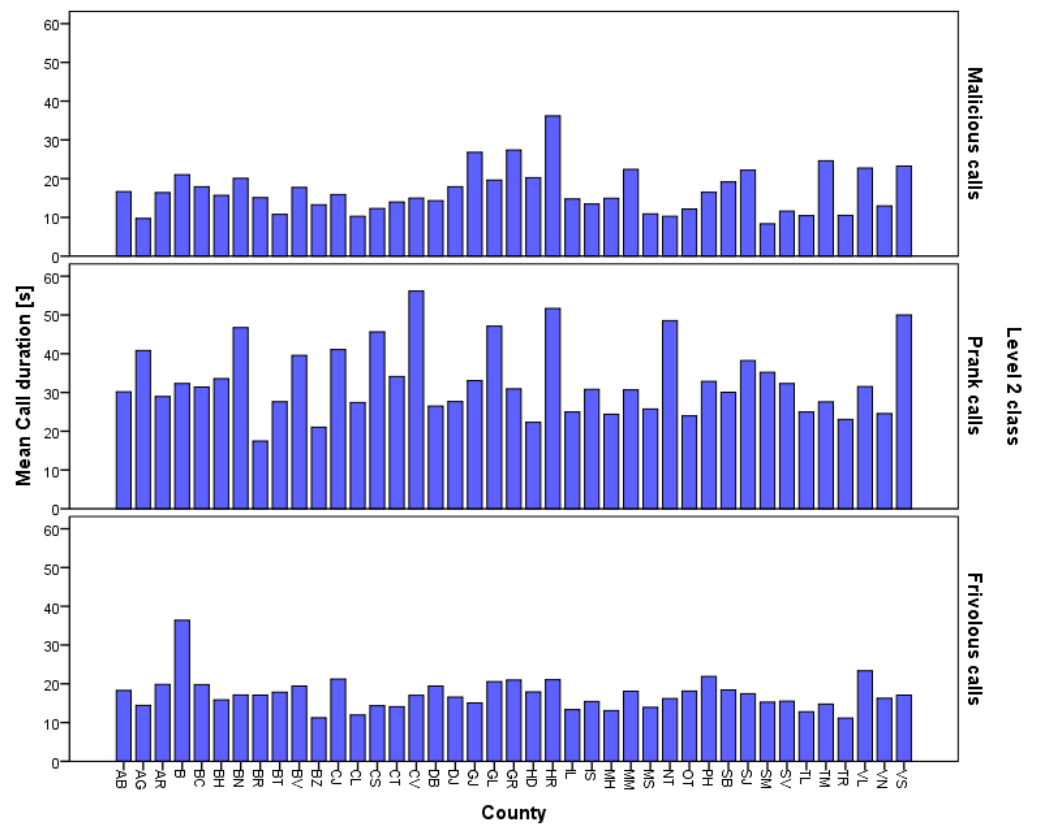

Figure 10. Mean call duration

One can see that the longest call time and the smallest number of calls is registered for prank calls, due to the fact that, compared to adults, children find it hard to persuade an operator and because of that their calls take longer than the other types.

The distribution per hours of day and the day of week lead us to other important findings.

While the distribution per days of the week is almost the same, with a peak during Saturdays, the time distributions clearly indicate that the majority of children calls occur during adult working hours, when the children are not supervised.

Table 2. Abusive Calls distributions per days of the week

\begin{tabular}{|c|c|}
\hline Day of the week & No. of abusive calls \\
\hline Sunday & 19,584 \\
\hline Monday & 19,367 \\
\hline Tuesday & 18,407 \\
\hline Wednesday & 17,874 \\
\hline Thursday & 18,855 \\
\hline
\end{tabular}


Quantitative Data Analysis on Abusive Calls Generated by Children to 112

\begin{tabular}{|c|c|}
\hline Day of the week & No. of abusive calls \\
\hline Friday & 17,927 \\
\hline Saturday & 20,208 \\
\hline
\end{tabular}

No of abusive calls

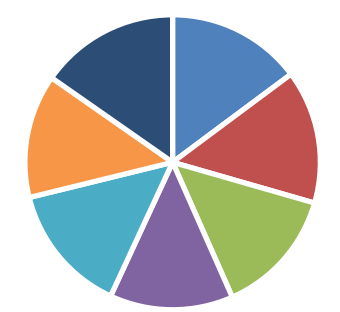

- Sunday - Monday " Tuesday " Wednesday
- Thursday - Friday - Saturday

Figure 11. Abusive Calls distributions per days of the week

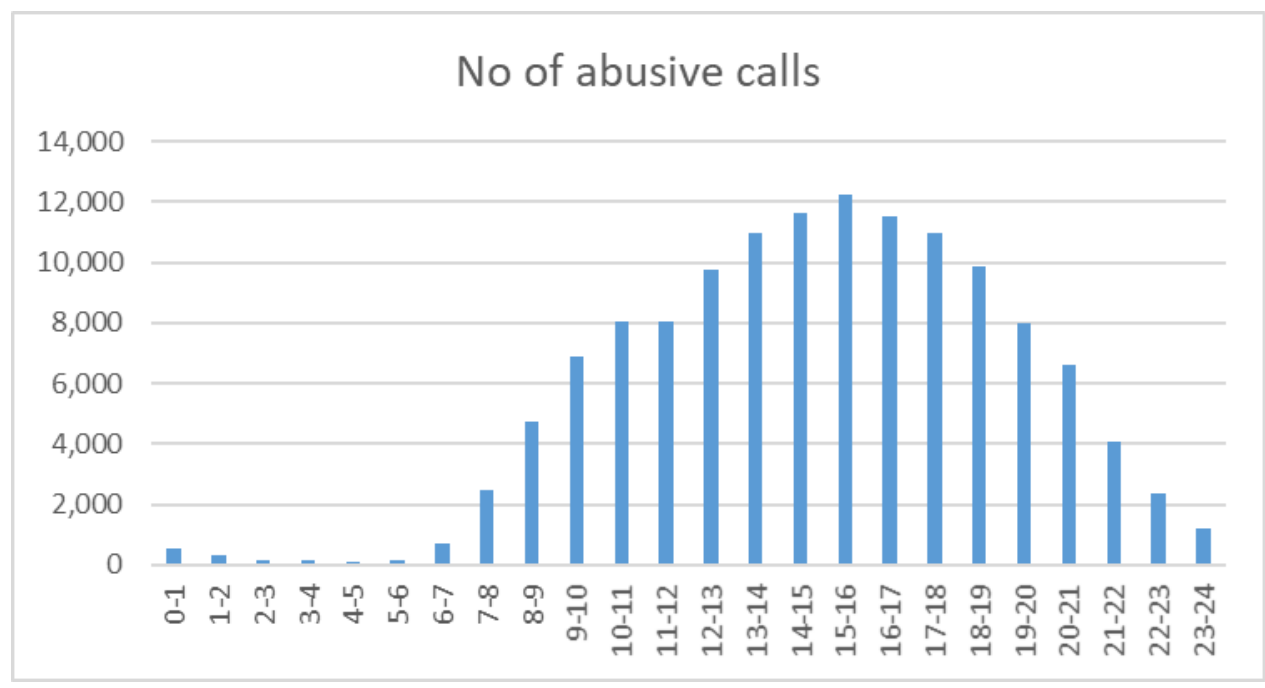

Figure 12. Abusive Calls distributions per hours

DOI: $10.24818 / 18423264 / 54.2 .20 .13$ 
Ionel-Sorinel Vasilca, Mihail Bărănescu, Marius Profiroiu, Lasse Berntzen, Codruta Chis, Madlena Nen

By using thematic maps, we obtained the geographic representation of the counties' clusters.

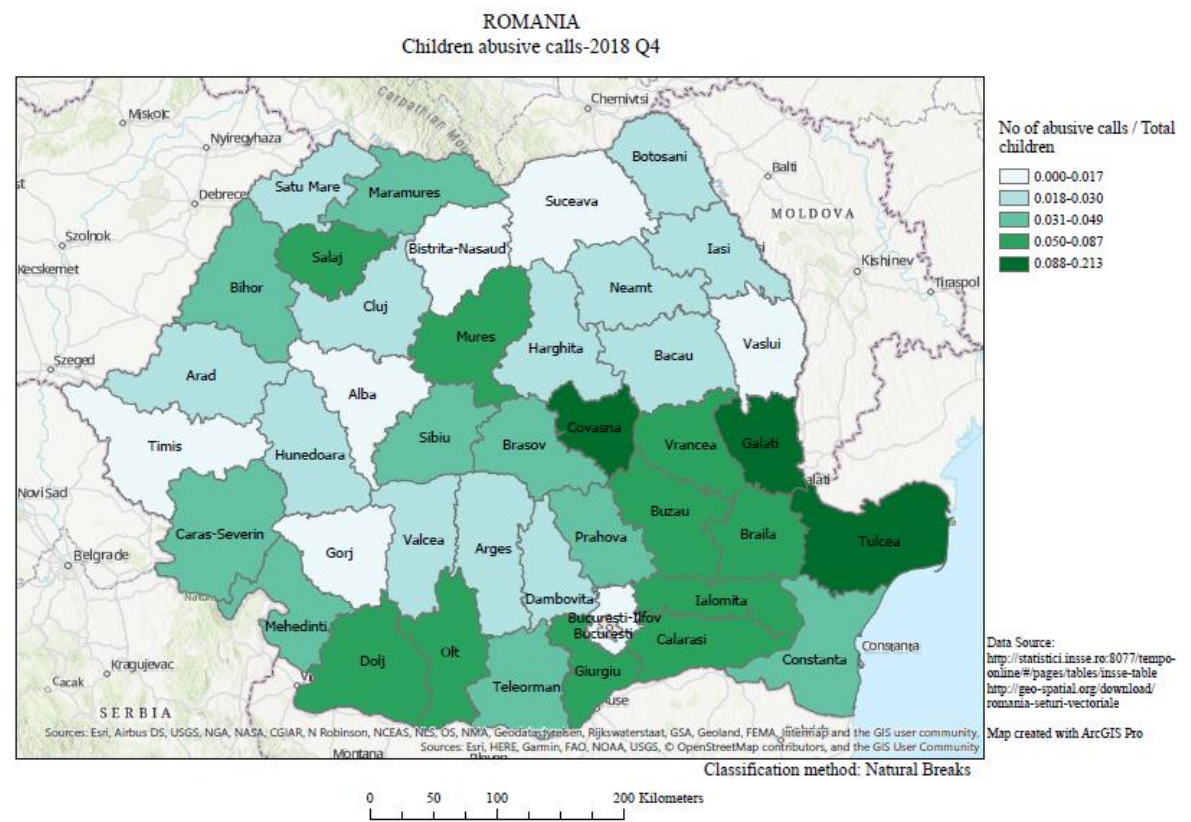

Figure 13. Children abusive calls distributions per county

The geographical representation above supports the 112 administrator towards first targeting children population of Galați, Tulcea, Covasna, Mureș, Sălaj, Dolj, Giurgiu and Călărași (http://www.recensamantromania.ro).

\section{Conclusions}

In this paper, we used an econometric model for testing the relationship between the waiting time, duration and the number of abusive calls generated by children and adults, by running the eView regression equation. Our purpose was to see which were the most relevant actions the administrator of 112 should take in order to increase the call centres' performance.

Our results showed that the highest number of abusive calls originated by children are Frivolous Calls. Furthermore, we discovered an important relationship between decreasing the number of calls answered by an operator and the overall call waiting time. This is why the most important measure that needs to be taken by the administrator of the 112 system is to decrease the overall number of calls answered by 112 operators.

In order to fulfill this objective, we offer some legislative, operational and technical solutions.

From a legislative perspective, it is necessary to ask that the purchase of prepaid SIM cards should only be possible following an owner identity declaration. 
Quantitative Data Analysis on Abusive Calls Generated by Children to 112

If we consider the distribution of calls per county, days of the week and hours of the day, the administrator could rebalance the operational shifts and the number of operators so as to better cover the busiest time (Chromy, Kavacky \& Baronak, 2017). This could also be achieved by adopting certain technical solutions for routing calls between all available operators from across the entire country (EENA Next Generation 112 Long Term Definition, 2013). This technical solution is actually part of a modernization project initiated by the 112 administrator (https://www.sts.ro/ro/comunicate-de-presa/comunicat-de-presa1565777280, 2019).

One must not forget that the main objective of the 112 service is to dispatch the most suitable resources as fast as possible in order to save people's lives (Artman \&Wærn, 1999).

Anyway, the most important measure is to educate the population on the meaning of the 112 emergency number and when to initiate such calls, in an effort at reducing Frivolous Calls and also decrease the number of Malicious and Prank Calls.

\section{REFERENCES}

[1] Artman, H. \& Wærn, Y. (1999), Distributed Cognition in an Emergency CoOrdination Center . Cognition, Technology \& Work. 1. 237-246.

10.1007/s101110050020;

[2] Bates, D.M. \& Watts, D.G. (1988), Nonlinear Regression Analysis and Its Applications. John Wiley, New York. http://dx.doi.org/10.1002/9780470316757;

[3] Chromy, E., Kavacky, M. \& Baronak, I. (2017), Call Center Optimization Step by Step; 40th International Conference on Telecommunications and Signal Processing (TSP), Barcelona, 2017, pp. 119-123, doi: 10.1109/TSP.2017.8075949; [4] Cromdal, J., Landqvist, H., Persson-Thunqvist, D.\& Osvaldsson, K.(2012), Finding out What's Happened: Two Procedures for Opening Emergency Calls; Sage Journals, Discourse Studies, Vol. 4, Issue 4, https://doi.org/10.1177/1461445612439960;

[5] Deaton, J.D. (2008), High Altitude Platforms for Disaster Recovery:

Capabilities, Strategies and Techniques for Emergency Telecommunications.

$J$ Wireless Com Network. https://doi.org/10.1155/2008/153469;

[6] Eriksson, M. (2010), Conceptions of Emergency Calls: Emergency

Communication in an Age of Mobile Communication and Prevalence of Anxiety. Journal of Contingencies and Crisis Management, 18: 165-174.

doi:10.1111/j.1468-5973.2010.00613.x;

[7] Honigman, L.S., Wiler, J.L., Rooks, S., Ginde, A.A. (2013), National Study

of Non-urgent Emergency Department Visits and Associated Resource

Utilization. The Western Journal of Emergency Medicine

14(6):609616.doi:10.5811/westjem.2013.5.16112;

DOI: 10.24818/18423264/54.2.20.13 
Ionel-Sorinel Vasilca, Mihail Bărănescu, Marius Profiroiu, Lasse Berntzen, Codruta Chis, Madlena Nen

[8] Howitt, D. \& Cramer, D. (2011), Introduction to SPSS Statistics in Psychology for Version 19 and Earlier; Prentice Hall;

[9] Lee, A., Lau, F.-L., Hazlett, C. B., Kam, C.-W., Wong, P., Wong, T.-W.\& Chow, S. (2000), Factors Associated with Non-Urgent Utilization of Accident and Emergency Services: A Case-control Study in Hong Kong. Social Science \& Medicine, Volume 51, Issue 7, October 2000, Pages 1075-1085, Elsevier, https://doi.org/10.1016/S0277-9536(00)00039-3;

[10] Lehm, K. K., Andersen, M. S. \& Riddervold, I. S. (2017), Non-urgent Emergency Callers: Characteristics and Prognosis; Prehospital Emergency Care, 21:2, 166-173, DOI: 10.1080/10903127.2016.1218981;

[11] Moore, S. \& McCabe, A. E. (1996), Children learning to Use the Telephone: Emergency and Non-emergency Calling. Canadian Journal of Behavioural Science / Revue canadienne des sciences du comportement, 28(1), 61-69. https://doi.org/10.1037/0008-400X.28.1.61;

[12] Russo, R. (2003), Statistics for the Behavioural Sciences; Psychology Press, London, https://doi.org/10.4324/9780203641576;

[13] Scott, D., Brandow, C., Hobbins, J., Nilsson, S. \& Enander, A. (2015), Capturing the Citizen Perspective in Crisis Management Exercises: Possibilities and Challenges; International Journal of Emergency Services, Vol. 4 No. 1, pp. 86-102. https://doi.org/10.1108/IJES-12-2014-0024;

[14] Vertesi, L. (2004), Does the Canadian Emergency Department Triage and Acuity Scale Identify Non-Urgent Patients Who Can Be Triaged away from the Emergency Department?. Canadian Journal of Emergency Medicine, 6(5), 337342. doi:10.1017/S1481803500009611;

[15] Widiatmoko, D., Machen, I., Dickinson, A., Williams, J. \& Kendall, S. (2008), Developing a New Response to Non-urgent Emergency Calls: Evaluation of a Nurse and Paramedic Partnership Intervention. Primary Health Care Research \& Development, 9(3), 183-190. doi:10.1017/S1463423608000765;

[16] EENA Operations Committee False Emergency Calls

https://eena.org/document/false-emergency-calls;

[17] EENA Next Generation 112 Technical Committee (2013), EENA Next

Generation 112 Long Term Definition; https://eena.org/document/ng112-longterm-definition-standard-for-emergency-services/;

[18] ITU-T (2008), Recommendation E.161.1 - Guidelines to select Emergency

Number for public telecommunications networks. International

Telecommunications Union, p. 4 ,

https://www.ietf.org/lib/dt/documents/LIAISON/file562.pdf;

[19] https://www.sts.ro/ro/statistici-112;

[20] https://www.sts.ro/ro/comunicate-de-presa/comunicat-de-presa1565777280;

[21] http://www.recensamantromania.ro. 